\title{
PRELIMINARY ESTIMATE OF THE RESERVOIR AGE IN THE LAGOON OF VENICE
}

\author{
$\mathrm{U} Z$ Zoppi $^{1} \bullet \mathrm{A} \mathrm{Albani}^{2} \bullet \mathrm{A}^{\mathrm{J}}$ Ammerman $^{3} \bullet \mathrm{QHua}^{1} \bullet \mathrm{E} \mathrm{M} \mathrm{Lawson}^{1} \bullet \mathrm{R} \mathrm{Serandrei} \mathrm{Barbero}^{4}$
}

\begin{abstract}
The Lagoon of Venice was formed about 6000 years ago due to the marine transgression associated with the late Pleistocene sea level rise. Already by the time of the Republic of Venice (727-1797 AD) it was recognized that the future of the city and its many historical buildings was strongly correlated with the future of the lagoon itself. During the centuries many engineering projects such as modification of the fluvial systems, construction of coastal barriers, and dredging of navigation channels were carried out to preserve the lagoonal environment. The present-day lagoon is the result of all these processes and covers an area of $540 \mathrm{~km}^{2}$ with an average depth of $0.6 \mathrm{~m}$. A series of radiocarbon age determinations carried out on material obtained from cores collected in the Lagoon of Venice indicate within the sedimentary units the existence of a number of discontinuities and slumping events due to the highly active lagoonal environment. The evaluation of data obtained from a variety of different materials - both terrestrial and marine - allowed us to determine for the first time the marine reservoir effect in the lagoon of Venice. The discussion includes a comparison with other relevant measurements and a possible explanation to the relatively high reservoir age (1200-1300 yr).
\end{abstract}

\section{INTRODUCTION}

Both Attila the Hun's brutal invasion in $452 \mathrm{AD}$ and the Lombard invasion in $568 \mathrm{AD}$ sent an influx of refugees streaming to the small islands of the lagoons lining the western coast of the Adriatic Sea, augmenting the fisherman population that already lived there. Unlike the Huns, the Lombards came to stay, establishing an Italian kingdom based in Pavia in north central Italy. As a result, with their mainland settlements permanently occupied by the invaders, more of the refugees elected to stay as permanent residents of the lagoon.

In $726 \mathrm{AD}$ a wave of unrest swept through the communities of Italy that remained subject to the Byzantine Empire based in Constantinople (modern-day Istanbul). The rebellious period passed away quickly and the entire episode might have been forgotten were it not for the particular event in Venice where in $727 \mathrm{AD}$ a local leader was elected with the Latin title of Dux (or, in the Venetian dialect, Doge). The process of electing a local Doge was continued after his death, making him the first elected leader of a republic that was to survive almost 1100 years until 12 May, 1797 AD, when the members of the Great Council of Venice resolved to dissolve the Republic and surrender the city to Napoleon.

The remarkable story of Venice and its inhabitants is interwoven with the story of the lagoon itself. High waters and tides, erosion and pollution, physical, and socioeconomic deterioration all represent elements of risk and danger that, although distinct, are closely interconnected and intricately bound together. The world was made once again aware of this during the dramatic flood of 4 November, 1966 AD when Venice and the other historic towns and villages in the lagoon were completely submerged under more than a meter of water.

An appropriate morphological restoration program-for example the dredging of lagoon channels, the reconstruction and protection of typical lagoon environments like salt marshes and mud flats, the restoration of minor islands, the re-opening of channels in the reclaimed areas, and the planting of eelgrass on the lagoon bed-must be supported with a large body of studies and experimental activities aimed at understanding the phenomena and processes associated with the ecosystem. Several

\footnotetext{
${ }^{1}$ ANSTO, Physics Division, Private Mail Bag 1, Menai NSW 2234, Australia. Email: ugo@ ansto.gov.au.

${ }^{2}$ School of Geology, University of NSW, Sydney NSW 2052, Australia

${ }^{3}$ Department of Classics, Colgate University, Hamilton N.Y. 13346, USA

${ }^{4}$ Istituto per lo Studio della Dinamica delle Grandi Masse, CNR, 30125 Venezia, Italy
}

(C) 2001 by the Arizona Board of Regents on behalf of the University of Arizona Radiocarbon, Vol 43, Nr 2A, 2001, p 489-494

Proceedings of the 17 th International ${ }^{14} \mathrm{C}$ Conference, edited by I Carmi and $\mathrm{E}$ Boaretto 
studies on the present and past environments have been successfully conducted by means of benthic foraminifera (Albani et al. 1998; Albani and Serandrei Barbero 1990; Serandrei Barbero et al. 1997).

Foraminifera are marine unicellular organisms that secrete a test (shell) of calcium carbonate. At the death of the organism these tests become part of the sediment and therefore form a permanent record of the environmental conditions present during their life. Foraminifera are sensitive to different water qualities and, as they are abundant as number of species and as number of individuals, are very suitable for coastal assessment studies. Although the foraminiferal tests offer an ideal tool to investigate environmental changes and understand the sedimentary history of selected parts of the lagoon, the correlation with well established techniques based on land remnants and therefore the determination of an absolute time scale have been difficult because of the reservoir effect related to the marine environment.

This paper will present radiocarbon measurements aimed at determining the reservoir effect for the lagoon of Venice.

\section{SAMPLE SELECTION}

The Lagoon of Venice was formed during the Flandrian transgression (Gatto and Carbognin 1981) and its deposits lie on the upper Adriatic paleoplain of Wurmian age. Although in some areas the base of the succession is not clearly identifiable due to the continental character of the early sediments, it was established that the boundary occurs widely at around $5.0 \mathrm{~m}$ below sea level and that the average sedimentation rate in the lagoon as a whole is about $7 \mathrm{~cm}$ per century (Ammerman et al. 1999).

In 1993, a series of archaeological excavations were carried out in the Lagoon of Venice at the Island of S. Francesco del Deserto, north of the Basilica (Figure 1), by the Soprintendenza per i Beni Ambientali e Architettonici di Venezia (Cafiero 1993). The excavation site consisted of a number of rectangular trenches generally 3-4 meters deep with the surrounding ground at $1.2 \mathrm{~m}$ above mean sea level. The excavations were wholly within the lagoonal sediments that in this area attain the thickness of 5-6 m. They revealed a lagoon sedimentary sequence containing the remains of a settlement from the fifth century (Ammerman et al. 1995; Serandrei Barbero et al. 1997).

From trench S10 (Figure 1), $8 \mathrm{~m}$ long, $3 \mathrm{~m}$ wide and $4 \mathrm{~m}$ deep, a few horizons were sampled. From level (9043) at $-2.60 \mathrm{~m}$ we collected a leaf of laurel (sample OxA-8629) and at $-2.70 \mathrm{~m}$ a number of foraminiferal tests (sample OZE696) of the genera Ammonia, Helenina, and Cribononion (Albani and Serandrei Barbero 1990). Assuming a constant sedimentation rate of $7 \mathrm{~cm}$ per century, a separation of $10 \mathrm{~cm}$ would correspond to an age difference of 140 years. However, the interval of $10 \mathrm{~cm}$ under consideration did not show any change in lithological character or any discontinuity. In fact, both samples represent the same sedimentological horizon. Therefore, we believe that the age difference should be much less than the hypothetical 140 years obtained with a constant sedimentation rate. Level (9046) at $-3.30 \mathrm{~m}$ contained an abundant fauna of ostracods (sample OZE697) and foraminifera of the genera Ammonia and Helenina (sample OZE698). The level (9047) at $-3.50 \mathrm{~m}$ still contained foraminiferal tests (mainly genus Ammonia, sample OZE699). Below these horizons, at $3.85 \mathrm{~m}$, the lagoonal deposits are replaced by sediment with swamp characteristics which is considered to preceding the establishment of the Lagoon proper. 


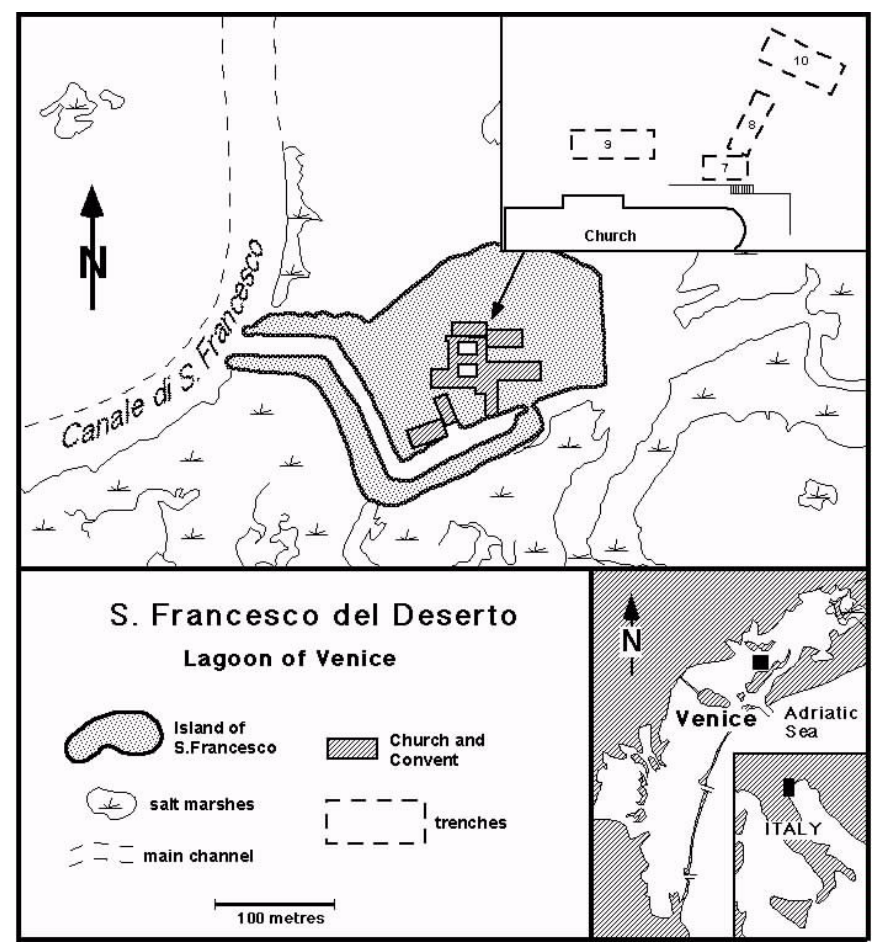

Figure 1 The excavation site at the Island of San Francesco del Deserto in the Lagoon of Venice

\section{${ }^{14} \mathrm{C}$ DATING}

Samples OZE696 to OZE699 were prepared and measured at the accelerator mass spectrometry (AMS) facility at ANSTO (Sydney, Australia; Lawson et al. 2000). All samples were washed with de-ionized water in a sonic bath and oven-dried at $60^{\circ} \mathrm{C}$ for 2 days before being converted to $\mathrm{CO}_{2}$ by hydrolysis using a modified method of Hoefs (1987): a reaction with $85 \% \mathrm{H}_{3} \mathrm{PO}_{4}$ in a sealed sidearm vessel maintained at $60^{\circ} \mathrm{C}$ overnight. Finally, graphite targets were prepared by reducing $\mathrm{CO}_{2}$ using zinc $\left(400^{\circ} \mathrm{C}\right)$ and iron $\left(600^{\circ} \mathrm{C}\right)$ catalysts in the presence of a small amount of hydrogen. The technical details of these methods can be found in Hua et al. (2001).

The ${ }^{14} \mathrm{C} /{ }^{13} \mathrm{C}$ isotopic ratio was measured relative to the internationally accepted HOxI standard material (Stuiver 1983). After the AMS measurement, the remaining graphite was re-collected for $\delta^{13} \mathrm{C}$ determination with a stable isotope mass spectrometer. Corrections were applied for the machine background, for the contamination introduced in the preparation of the graphite target and for isotopic fractionation. The results of the ${ }^{14} \mathrm{C}$ dating are listed in Table 1.

\section{DISCUSSION}

The direct comparison of samples OxA-8629 and OZE696 retrieved from the same horizon will give us an estimate of the reservoir age for the Lagoon of Venice. Figure 2 shows how to derive the marine conventional age corresponding to the laurel leaf dated at $1895 \pm 40 \mathrm{BP}$. The difference between this marine conventional age $(2255 \pm 45 \mathrm{BP})$ and the measured radiocarbon age (3190 \pm 40 BP) constitutes $\Delta \mathrm{R}$. In this case $\Delta \mathrm{R}=935 \pm 60 \mathrm{yr}$. Taking under consideration the constant sedimen- 


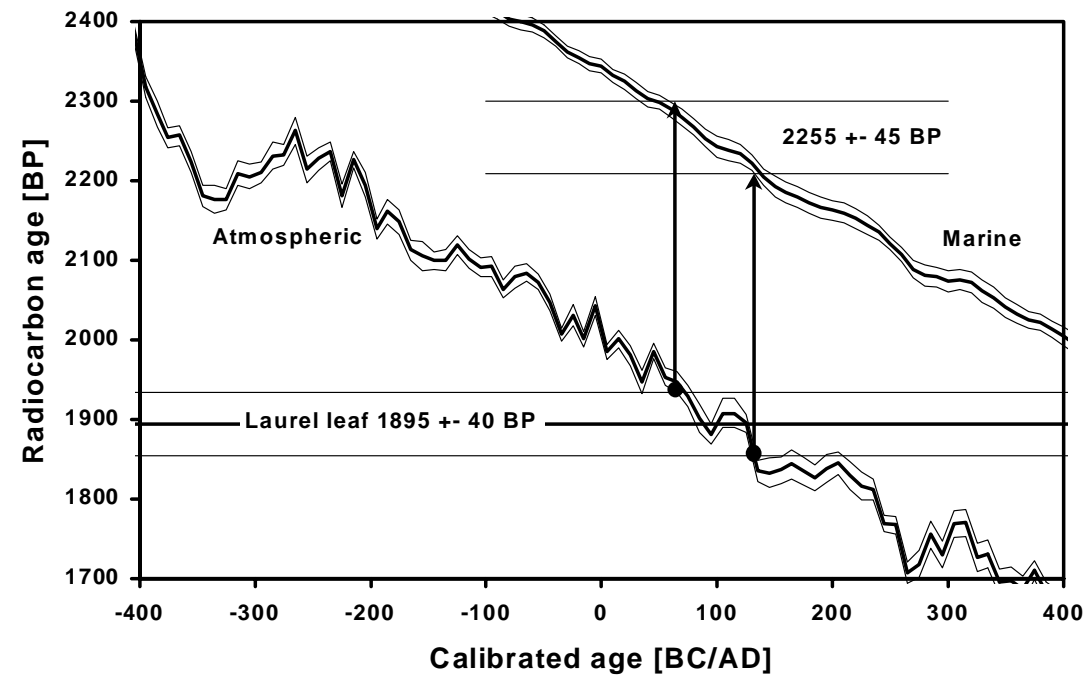

Figure 2 The comparison of the atmospheric and marine calibration curves (Stuiver et al. 1998a, 1998b) allows the determination of the corresponding marine conventional age which would give the same calibrated age as the laurel leaf dated at $1895 \pm 40 \mathrm{BP}$.

tation rate of $7 \mathrm{~cm}$ per century this value should be lowered by 140 years to $\Delta \mathrm{R}=800 \pm 60 \mathrm{yr}$. The actual $\Delta \mathrm{R}$ value is situated between the two estimates presented here and seems quite high, especially when compared with other $\Delta \mathrm{R}$ estimates carried over in nearby locations (Siani et al. 2000). For example, the result $\Delta \mathrm{R}=306 \mathrm{yr}$ was obtained for a shell (Chamalea gallina) collected alive in 1945 at the Lido in Venice. However, it must be noted that the collection site is on the open sea side of the lagoon barrier and therefore subjected to a much lesser extent to the particular lagoonal environment dominated by the input of freshwater bearing ${ }^{14} \mathrm{C}$ free residues derived from the erosion of the Dolomites. Similar high values were also measured in the San Francisco Bay (Ingram and Southon 1996) where the groundwater near the Sacramento River showed a ${ }^{14} \mathrm{C}$ concentration equivalent to $65 \mathrm{pMC}$. Finally, only with this high reservoir effect it is possible to obtain for the excavated trench a consistent chronological sequence (Figure 3), which is compatible with the sedimentation rate of $7 \mathrm{~cm}$ per century determined by Ammerman et al. (1999).

Table 1 The measured ${ }^{14} \mathrm{C}$ ages for the samples collected in trench S10 (Figure 1). The analysis of samples OZE696 to OZE699 was performed at ANSTO (Lawson et al. 2000) and is presented in this paper. Samples with the prefix OxA were measured at the Oxford Radiocarbon Accelerator Unit (OXA-6784: Ammerman et al. 1999; OxA-8629 and OxA-8630: unpublished).

\begin{tabular}{lllcc}
\hline Depth & Code & Material & $\delta^{13} \mathrm{C}(\mathrm{PDB})$ & ${ }^{14} \mathrm{C}$ age \\
\hline$-2.3 \mathrm{~m}$ & OxA-6784 & Wood (Roman pipe) & $-22.8 \% o$ & $1785 \pm 50 \mathrm{BP}$ \\
$-2.6 \mathrm{~m}$ & OxA-8629 & Laurel leaf & $-27.6 \%$ & $1895 \pm 40 \mathrm{BP}$ \\
$-2.7 \mathrm{~m}$ & OZE696 & Foraminifera & $-5.14 \% \circ$ & $3190 \pm 40 \mathrm{BP}$ \\
$-3.3 \mathrm{~m}$ & OZE697 & Ostracods & $-6.69 \%$ & $4450 \pm 40 \mathrm{BP}$ \\
$-3.3 \mathrm{~m}$ & OZE698 & Foraminifera & $-5.46 \% \circ$ & $4510 \pm 40 \mathrm{BP}$ \\
$-3.5 \mathrm{~m}$ & OZE699 & Foraminifera & $-2.60 \%$ & $4930 \pm 40 \mathrm{BP}$ \\
$-4.8 \mathrm{~m}$ & OxA-8630 & Plant fibres & $-26.5 \% \circ$ & $4880 \pm 45 \mathrm{BP}$ \\
\hline
\end{tabular}


Studies conducted on a number of salt marshes (Bonardi 1997; Bonardi et al. 1998) have revealed a series of different paleoenvironments. During the process of determining their chronology, a mismatch became evident between ages determined using shell fragments of marine gastropods and benthic foraminifera. A possible explanation might be related to the biological diversities such as dissimilar shell secretion and/or feeding modes that could cause a species-dependent reservoir age. Samples OZE697 and OZE698 show that among foraminifera, if interspecies differences exists, these are not strong enough to induce different reservoir ages.

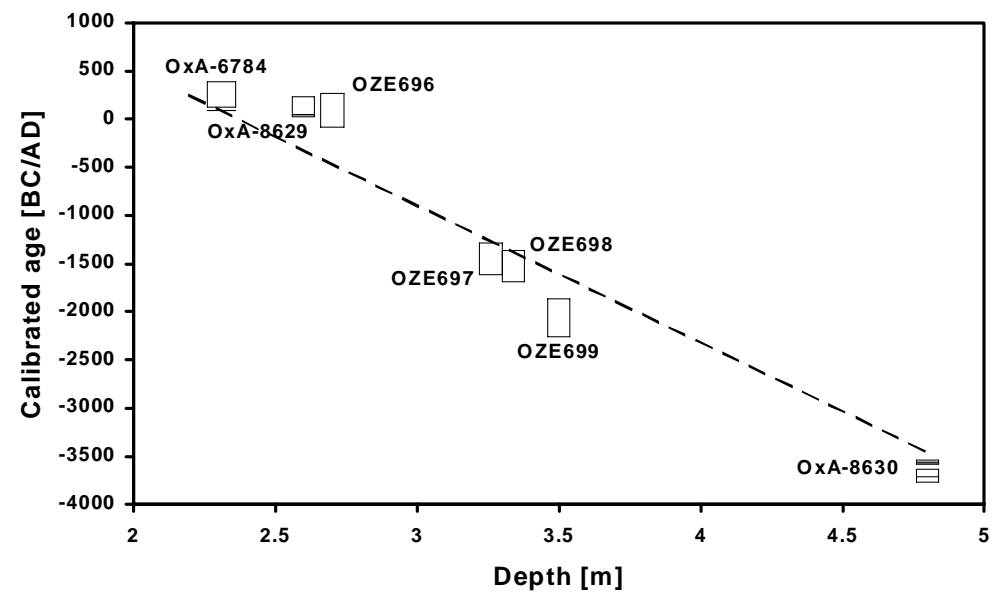

Figure 3 The 2- $\sigma$ calibrated age ranges for the samples presented in Table 1. The calibration was performed using the CALIB software (Stuiver and Reimer 1993) and the calibration curves of Stuiver et al. (1998a, 1998b). For the marine samples $\Delta R=935 \pm 60 \mathrm{yr}$ was used. The broken line represents the mean sedimentation rate of $7 \mathrm{~cm}$ per century (Ammerman et al. 1999).

\section{CONCLUSION}

Preliminary results show that the reservoir age in the lagoon of Venice is as high as 1200 years. Additional work is already planned to confirm this hypothesis. This includes the sampling of more cores and, when a lens of plants fibres is recovered, the dating of parallel foraminifera samples. Moreover, we intend to further assess interspecies differences between various carbonate-secreting organisms.

\section{REFERENCES}

Albani AD, Serandrei Barbero R. 1990. I foraminiferi della Laguna e del Golfo di Venezia. Memorie di Scienze Geologiche (Università di Padova) 42:271-341.

Albani AD, Favero VM, Serandrei Barbero R. 1998. Distribution of Sediment and Benthic Foraminifera in the Gulf of Venice, Italy. Estuarine, Coastal and Shelf Science 46(2):252-65.

Ammerman AJ, De Min M, Housley R, McClennen CE. 1995. More on the origin of Venice. Antiquity 69:50110 .

Ammerman AJ, McClennen CE, De Min M, Housley R. 1999. Sea-level change and the archaeology of early Venice. Antiquity 73:303-12.

Bonardi M. 1997. Studio dei processi evolutivi di alcune barene della Laguna di Venezia (bacino Nord) in relazione alle variazioni del livello marino. Rapporto finale. Consorzio Venezia Nuova- C.N.R. Istituto per lo Studio della Dinamica delle Grandi Masse. 65 p.

Bonardi M, Tosi L, Serandrei Barbero R, Canal E, Cavazzoni S, Albani AD. 1998. Evoluzione e cronologia di alcune barene della Laguna di Venezia in relazione alle variazioni del livello marino: banca dati. CNR-ISDGM, Techn. Note 188.100 p.

Cafiero F. 1993. San Francesco del Deserto-Relazione di scavo eseguita per la Sopraintendenza per i Beni Ambientali ed Architettonici di Venezia. Unpublished.

Gatto P, Carbognin L. 1981. The Lagoon of Venice: natural environmental trend and man-induced modifica- 
tion. Bulletin of Hydrological Science 26(4):379-91.

Hoefs J. 1987. Stable Isotope Chemistry. Third edition. Berlin: Springer-Verlag.

Hua Q, Jacobsen GE, Zoppi U, Lawson EM, Williams AA, Smith AM, McGann MJ. 2001. Progress in radiocarbon target preparation at the ANTARES AMS Centre. Radiocarbon. This issue.

Ingram BL, Southon JR. 1996. Reservoir ages in Eastern Pacific coastal and estuarine waters. Radiocarbon 38(3):571-82.

Lawson EM, Elliott G, Fallon J, Fink D, Hotchkis MAC, Hua Q, Jacobsen GE, Lee P, Smith AM, Tuniz C, Zoppi U. 2000. AMS at ANTARES - the first 10 years. Nuclear Instruments and Methods in Physics Research B172:95-9.

Serandrei Barbero R, Albani AD, Zecchetto S. 1997. Palaeoenvironmental significance of a benthic foraminiferal fauna from an archaeological excavation in the Lagoon of Venice, Italy. Palaeogeography, Palae- oclimatology, Palaeoecology 136:41-52.

Siani G, Paterne M, Arnold M, Bard E, Métivier B, Tisnerat N, Bassinot F. 2000. Radiocarbon reservoir ages in the Mediterranean Sea and Black Sea. Radiocarbon 42(2):271-80.

Stuiver M. 1983. Business meeting: international agreements and the use of the new oxalic acid standard. $R a$ diocarbon 25(2):793-5.

Stuiver M, Reimer PJ. 1993. Extended ${ }^{14} \mathrm{C}$ database and revised CALIB radiocarbon calibration program. $R a$ diocarbon 35(1):215-30.

Stuiver M, Reimer PJ, Bard E, Beck JW, Burr GS, Hughen KA, Kromer B, McCormac FG, van der Plicht J, Spurk M. 1998a. INTCAL98 radiocarbon age calibration 24,000-0 cal BP. Radiocarbon 40(3):104184.

Stuiver M, Reimer PJ, Brazunias TF. 1998b. High-precision radiocarbon age calibration for terrestrial and marine samples. Radiocarbon 40(3):1127-52. 